\title{
ANALISA UKURAN BUTIRAN SEDIMEN \\ PANTAI DESA AENG KABUPATEN TAKALAR DAN PANTAI PADONGKO KABUPATEN BARRU
}

\author{
*Hasdinar Umar, Taufiqur Rachman, Sabaruddin Rahman, Chairul Paotonan, A.Y. Baeda, Taufiqurrahman dan \\ Ilham Alkhaer \\ Departemen Teknik Kelautan Universitas Hasanuddin \\ *hasdinar_umar@unhas.ac.id
}

\begin{abstract}
Abstrak
Pantai merupakan daerah yang mudah mengalami perubahan secara fisik. Perubahan ini diakibatkan oleh proses alam maupun kegiatan manusia. Perubahan fisik yang umumnya terjadi di pantai adalah erosi dan sedimentasi. Proses dinamis yang terjadi di pantai merupakan akibat dari kombinasi berbagai gaya yang bekerja di pantai, yang meliputi gaya gelombang, arus, gerakan sedimen, angin dan sebagainya. Untuk menganalisis angkutan sedimen di daerah pantai, salah satu hal utama yang perlu diketahui adalah karakteristik sedimen pantai yaitu diameter butiran sedimen. Penelitian dilakukan di pantai yang rawan erosi dan sedimentasi, lokasi penelitian data sampel di beberapa titik yang diambil di area sekitar Pantai Desa Aeng Takalar dan Pantai Padongko Barru. Analisis yang dilakukan yaitu analisis distribusi butiran sedimen untuk mengetahui karakteristik sedimen yang ada di pantai. Hasil penelitian menunjukkan bahwa ukuran-ukuran butiran sampel sedimen di pantai di Desa Aeng Kabupaten Takalar adalah beberapa campuran pasir halus dan pasir sedang yang memiliki diameter 0,125 mm - 0,5 mm dan ukuran butiran sedimen di Pantai Padongko Kabupaten Barru adalah campuran pasir halus dan pasir sedang yang memiliki diameter $0,125-0,5 \mathrm{~mm}$.
\end{abstract}

Kata Kunci: Sedimen, Ukuran Butiran, Pantai.

\begin{abstract}
Beach is an area that is physically subject to change. This change is caused by natural processes and human activities. Physical changes that generally occur on the beach are erosion and sedimentation. The dynamic processes that occur at the beach are the result of a combination of various forces at work on the beach, which include the force of waves, currents, sedimentary movements, wind and so on. To analyze sediment transport in coastal areas, one of the main things that need to be known is the characteristic of coastal sediments likely diameter of sediment. The study was carried out on beaches prone to erosion and sedimentation, the location of sample data research at several points taken in the area around the Aeng Takalar Village Beach and Padongko Barru Beach. The analysis carried out is the analysis of the distribution of sediment grains to determine the characteristics of existing sediments on the beach. The results showed that the sizes of the sediment samples on the beach in Aeng Village, Takalar District were a mixture of fine sand and medium sand which had a diameter of $0.125 \mathrm{~mm}-0.5 \mathrm{~mm}$ and the size of the sediment grains on the Padongko beach, Barru District was a mixture of fine sand and medium sand which has a diameter of $0.125-0.5 \mathrm{~mm}$.
\end{abstract}

Keyword: Sediment, Grain Size, Beach.

\section{PENDAHULAN}

Pantai adalah bagian dari muka bumi yang diawali dari muka air laut rata-rata terendah sampai muka air laut rata-rata tertinggi. Wilayah pesisir pantai merupakan tempat pemusatan berbagai kegiatan, seperti permukiman, pertambakan, rekreasi dan sarana perhubungan. Meningkatnya kebutuhan dan persaingan dalam penggunaan lahan pantai memerlukan pemikiran yang seksama dalam mengambil keputusan guna 
pemanfaatan yang paling menguntungkan dari sumberdaya lahan yang terbatas, dan juga melakukan upaya konservasi lahan untuk penggunaan di masa mendatang [1].

Pantai merupakan daerah yang mudah mengalami perubahan secara fisik. Perubahan ini diakibatkan oleh proses alam maupun kegiatan manusia. Perubahan fisik yang umumnya terjadi di pantai adalah erosi dan sedimentasi. Erosi adalah hilangnya daratan di wilayah pesisir dan sedimentasi adalah timbulnya daratan baru di wilayah pesisir. Fenomena erosi maupun sedimentasi disebabkan oleh faktor alami dan manusia. Faktor alami diantaranya adalah arus laut, gelombang, kondisi morfologi/litologi dan vegetasi yang tumbuh di pantai. Adapun faktor yang disebabkan oleh aktivitas manusia adalah adanya bangunan baru di pantai, perusakan terumbu karang, penebangan atau penggunaan wilayah sabuk pantai (mangrove) untuk kepentingan lain seperti lokasi budidaya atau fasilitas lainnya [2].

Perubahan-perubahan yang terjadi di daerah pantai disebabkan oleh angkutan sedimen baik yang bergerak tegak lurus pantai maupun yang bergerak menyusuri pantai. Untuk menganalisis angkutan sedimen pantai diperlukan data analisis ukuran butiran sedimen pantai yang kemudian disesuaikan dengan tabel klasifikasi Wentworth untuk diameter butiran sedimen [3], sehingga dalam penelitian ini dilakukan pengujian tentang ukuran butiran sedimen pantai pada 2 (dua) lokasi pantai di Sulawesi Selatan yaitu Pantai Desa Aeng BatuBatu, Takalar dan Pantai Padongko, Barru.

\section{METODE}

Penelitian dilaksanakan di 2 (dua) lokasi pantai yang berada di Sulawesi Selatan yaitu Pantai Desa Aeng BatuBatu Kecamatan Galesong Utara Kabupaten Takalar dan Pantai Padongko Kelurahan Mangempang Kecamatan Barru Kabupaten Barru. Adapun metode pengambilan sampel sedimen dilakukan secara manual, dengan cara sebagai berikut [4][5]:

1. Penentuan lokasi pengambilan data sampel sedimen;

2. Menetukan titik pengambilan sedimen menggunakan GPS;

3. Memasang pipa pada titik yang telah ditentukan dan kemudian diberi tekanan hingga mencapai kedalaman tertentu;

4. Setelah pipa mencapai dasar yang telah ditentukan maka pipa ditarik agar sedimen dapat tertahan dalam pipa;

5. Kemudian sedimen yang tertangkap dikeluarkan dari lubang pipa;

6. Dilakukan pencatatan atau pemberian kode sampel agar lebih mudah dibedakan antara hasil sampel sedimen yang satu dengan yang lain.

Pantai Desa Aeng Takalar dan Pantai Padongko Barru merupakan lokasi pengambilan sampel sedimen di sepanjang pantai dengan jarak $\pm 1000 \mathrm{~m}$, dimana jarak antar titik $\pm 200 \mathrm{~m}$ dan jumlah masing-masing lokasi sebanyak 15 titik sampel. Alat yang digunakan untuk menentukan letak koordinat tiap titik yaitu GPS (Global Position Sistem). Untuk lebih jelas dapat dilihat pada Gambar 1 dan 2 berikut.

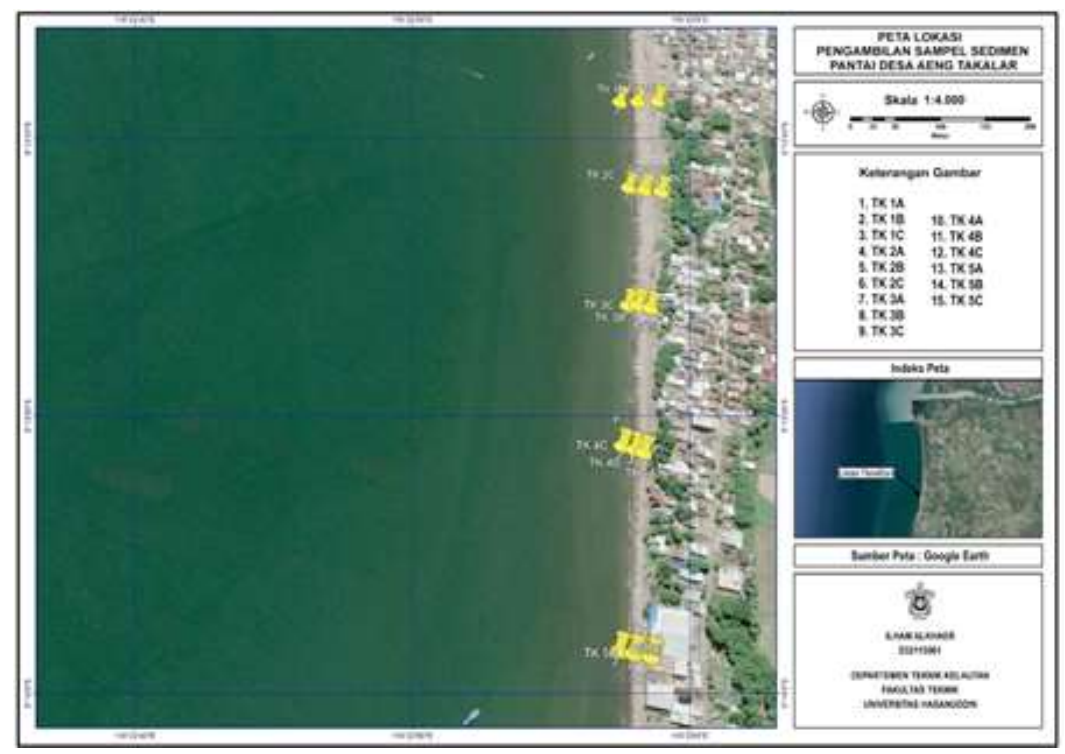

Gambar 1. Peta Titik Pengambilan Sampel Sedimen Pantai Desa Aeng Takalar copyright is published under Lisensi Creative Commons Atribusi 4.0 Internasional. 


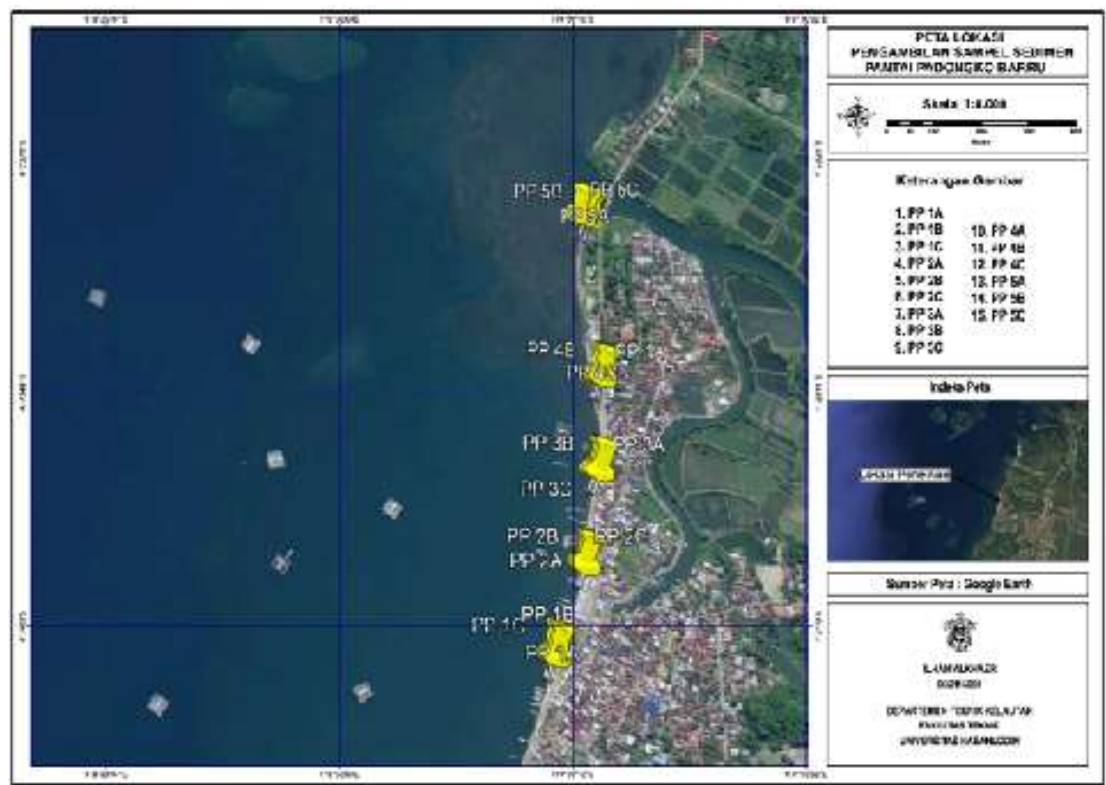

Gambar 2. Peta Titik Pengambilan Sampel Sedimen Pantai Padongko Barru

\section{HASIL DAN PEMBAHASAN}

Salah satu cara untuk menentukan variasai ukuran partikel-partikel pada sedimen dengan melakukan analisis diameter ukuran butiran sedimen, variasi tersebut dinyatakan dalam persentase dari berat kering total. Analisis diameter butiran sedimen dilakukan di Laboratorium Geoteknik Departemen Teknik Kelautan dengan menggunakan satu set ayakan/saringan berdiameter $2 \mathrm{~mm}, 1,18 \mathrm{~mm}, 0,85 \mathrm{~mm}, 0,6 \mathrm{~mm}, 0,425 \mathrm{~mm}, 0,3 \mathrm{~mm}$, $0,25 \mathrm{~mm}, 0,15 \mathrm{~mm}, 0,075 \mathrm{~mm}$, yang sebelumnya sampel telah dioven selama 24 jam dan melakukan pengayakan sampel selama 15 menit. Kemudian masing-masing butiran yang tertahan dalam saringan berat tertahan tersebut dihitung.

Hasil analisis ukuran butiran sedimen Pantai Aeng Kabupaten Takalar dapat diklasifikasikan berdasarkan sistem USCS (Unified Soil Classification System) sebagai berikut:

1. Pasir Kasar (Tertahan saringan No.10): $100 \%-100 \%=0 \%$;

2. Pasir Sedang (Lolos saringan No.10 dan tertahan saringan No.40): $100 \%-87,88 \%=12,12 \%$;

3. Pasir Halus (Lolos saringan No.40 dan tertahan saringan No.200): 87,88\% - 0\% =87,88\%;

4. Lempung (Lolos saringan No.200): $0 \%-0 \%=0 \%$.

Berdasarkan hasil analisis saringan butiran sedimen hampir semua sampel sedimen adalah pasir halus dan grafik distribusi sedimen Pantai Desa Aeng Takalar ditampilkan pada Gambar 3.

Berdasarkan grafik distribusi butiran sedimen pada Gambar 3 dapat disimpulkan bahwa sedimen yang ada di Pantai Desa Aeng Takalar merupakan campuran antara pasir halus dan pasir sedang dengan diameter butiran antara $0,125 \mathrm{~mm}-0,25 \mathrm{~mm}$ dan $0,25 \mathrm{~mm}-0,5 \mathrm{~mm}$.

Sedangkan hasil perhitungan analisis ukuran butiran sedimen di Pantai Padongko Barru dapat diklasifikasikan berdasarkan sstem USCS (Unified Soil Classification System ) sebagai berikut:

1. Pasir Kasar (Tertahan saringan No. 10): $100 \%-100 \%=0 \%$;

2. Pasir Sedang (Lolos saringan No.10 dan tertahan saringan No. 40): $100 \%-78.57 \%=21,43 \%$;

3. Pasir Halus (Lolos saringan No.40 dan tertahan saringan No. 200): 78,57\% - 0\% =78,57\%;

4. Lempung (Lolos saringan No. 200): $0 \%-0 \%=0 \%$.

Berdasarkan grafik distribusi butiran sedimen pada Gambar 4 dapat disimpulkan bahwa sedimen yang ada di Pantai Padongko Barru juga merupakan campuran antara pasir halus dan pasir sedang dengan diameter butiran antara $0,125 \mathrm{~mm}-0,25 \mathrm{~mm}$ dan $0,25 \mathrm{~mm}-0,5 \mathrm{~mm}$. 


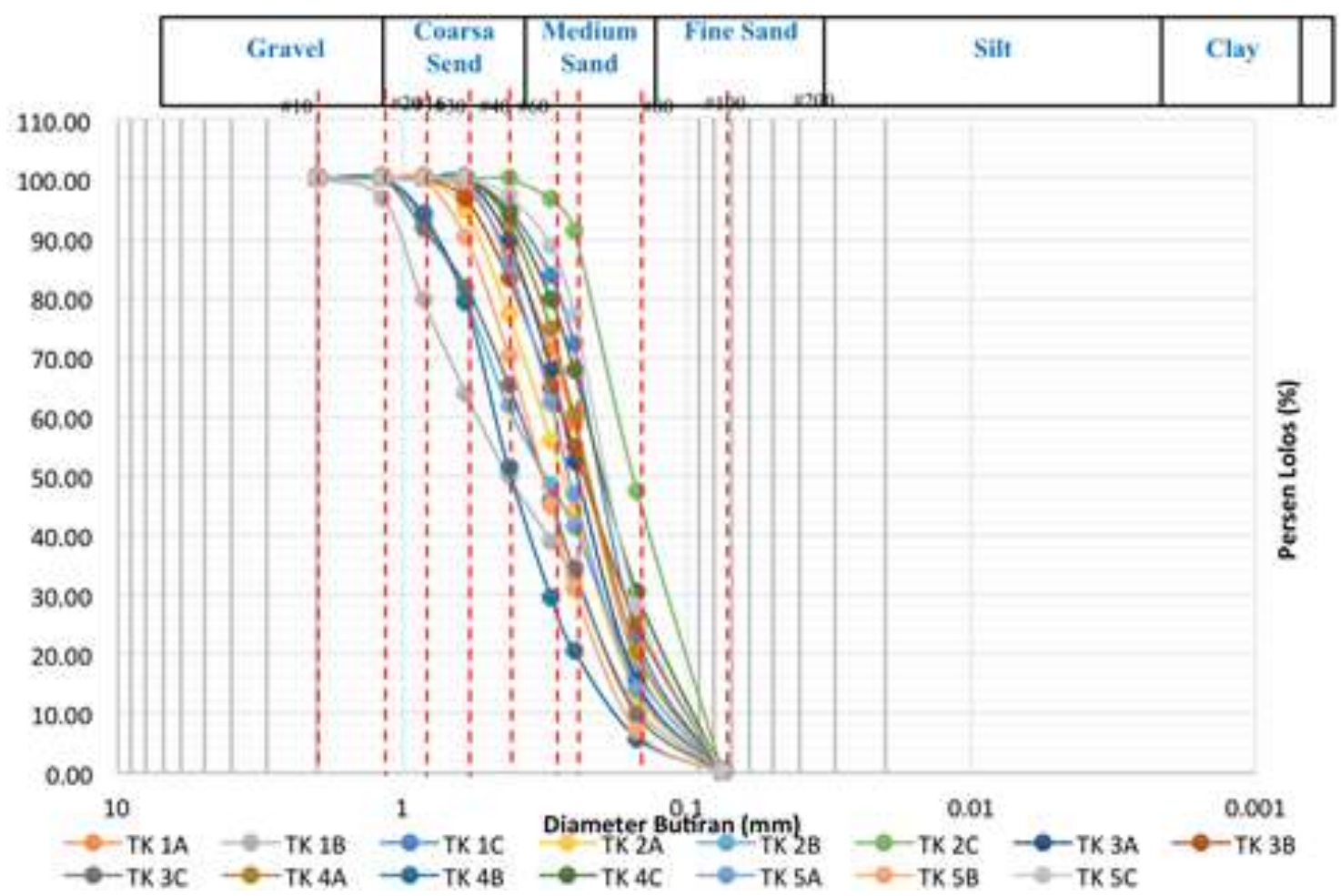

Gambar 3. Grafik Distribusi Sedimen Pantai Desa Aeng Takalar

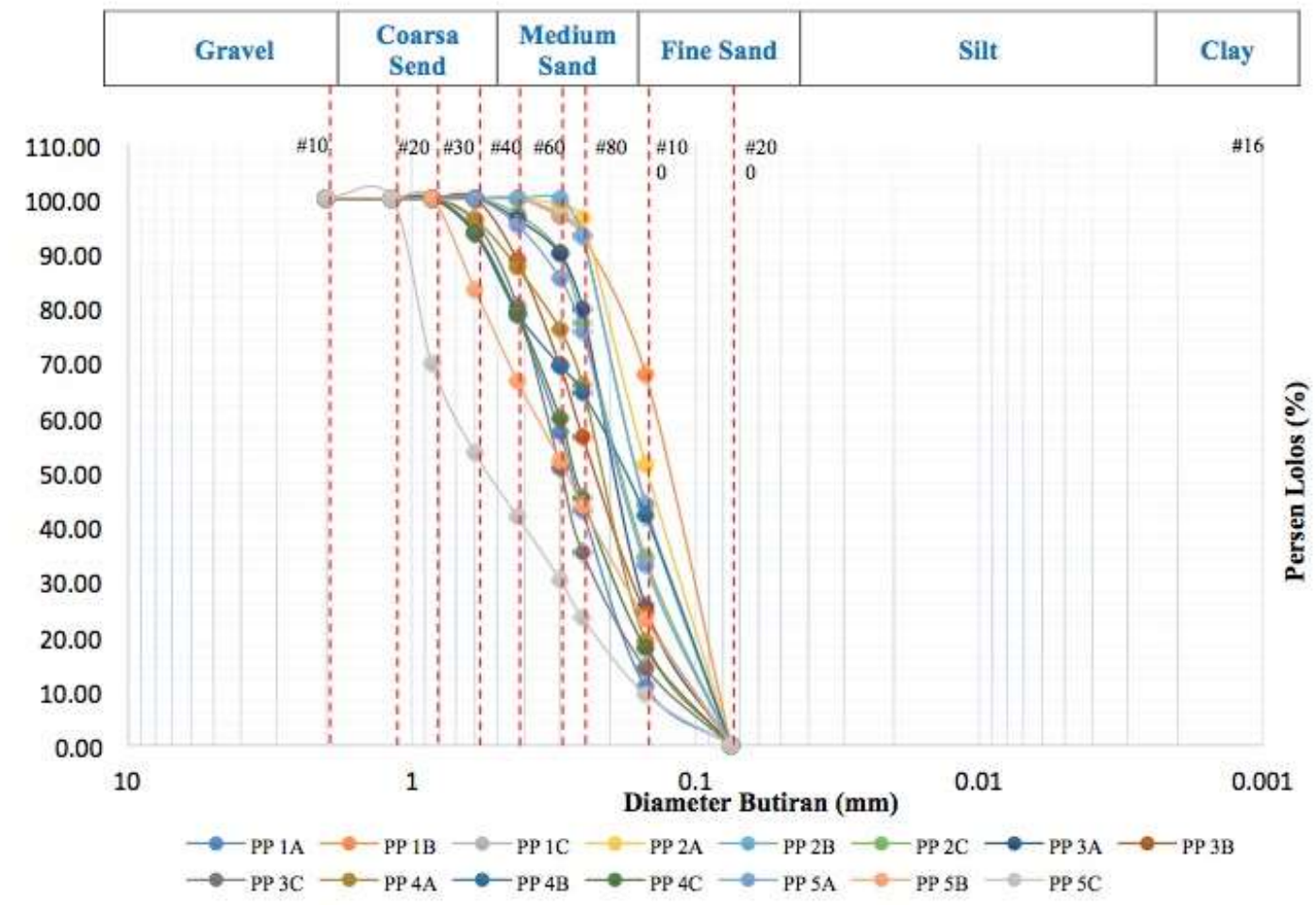

Gambar 4. Grafik Distribusi Sedimen Pantai Padongko Barru

\section{KESIMPULAN}

Berdasarkan hasil penelitian maka dapat disimpulkan bahwa:

1. Hasil analisis ukuran-ukuran butiran sampel sedimen di pantai di Desa Aeng Kabupaten Takalar adalah beberapa campuran pasir halus dan pasir sedang yang memiliki diameter $0,125 \mathrm{~mm}-0,5 \mathrm{~mm}$;

(c) (i) copyright is published under Lisensi Creative Commons Atribusi 4.0 Internasional. 
2. Hasil analisas ukuran butiran sedimen di pantai Padongko Kabupaten Barru juga merupakan campuran pasir halus dan pasir sedang yang memiliki diameter $0,125-0,5 \mathrm{~mm}$.

\section{UCAPAN TERIMA KASIH}

Artikel ini merupakan bagian hasil Penelitian Labo Based Education (LBE) Fakultas Teknik Universitas Hasanuddin Tahun Anggaran 2019 dengan judul Angkutan Sedimen Menyusur Pantai (Longshore Sediment Transport) pada Pantai Rawan Erosi dan Sedimentasi di Sulawesi Selatan. Penulis mengucapkan terima kasih kepada Fakultas Teknik Universitas Hasanuddin atas terlaksananya penelitian ini.

\section{DAFTAR PUSTAKA}

[1] Ayuningtyas, R, "Karakteristik Fisik Pantai Karst Kabupaten Gunungkidul", Skripsi. Universitas Indonesia, 2008.

[2] Shinta O.Y, dkk., "Studi Transpor Sedimen di Pantai Slamaran Pekalongan", Journal of Oceanography. Vol. 1, No. 2, Hal. 197-204, 2012.

[3] CERC, Shore Protection Manual, US Army Coastal Engineering Research Center, Washington (SPM, 1984), 1984.

[4] Umar, H., "Karakteristik Butiran Sedimen Pantai Rawan Erosi dan Sedimentasi di Sulawesi-Selatan", Seminar HATHI, 2016.

[5] Baeda, A.Y., 2011, Seismic and Tsunami Hazard Potential in Sulawesi Island, Journal of International Development and Cooperation, Vol. 17, No. 1, pp. 17-30. 2015. 